\title{
Can We Clarify the Causative Gene/Variants Underlying Familial Hypercholesterolemia and Improve Genetic Diagnosis Rate?
}

\author{
Mika Hori ${ }^{1,2}$
}

${ }^{1}$ Department of Endocrinology, Research Institute of Environmental Medicine, Nagoya University, Nagoya, Aichi, Japan ${ }^{2}$ Department of Endocrinology, Nagoya University Graduate School of Medicine, Nagoya, Aichi, Japan

\section{See article vol. 28: 000-000}

Familial hypercholesterolemia $(\mathrm{FH})$ is characterized by high low-density lipoprotein-cholesterol (LDL-C) levels, skin and tendon xanthomas, and premature coronary artery disease. $\mathrm{FH}$ is caused by pathogenic gene variants of the low-density lipoprotein receptor $(L D L R)$ and apolipoprotein $\mathrm{B}(A P O B)$, an LDL ligand, and proprotein convertase subtilisin/kexin type 9 (PCSK9), which degrades LDLR. Worldwide, > $95 \%$ of the variants that cause $\mathrm{FH}$ are in $L D L R$, $2 \%-11 \%$ are in $A P O B$, and $<1 \%$ are in $P C S K 9^{1)}$. However, $\mathrm{FH}$ varies genetically across geography, so it is necessary to assess $\mathrm{FH}$-causing variants in each population/country.

In the issue of the journal, Huang et al. investigated the spectrum of pathogenic variants of LDLR, APOB, PCSK9, LDLRAP1, ABCG5, and $A B C G 8$ in patients who were clinically diagnosed with FH in Taiwan ${ }^{2)}$. Of the 750 index cases, 443 pathogenic variants of $L D L R$ and $A P O B$ but not of PCSK9 were identified in approximately $60 \%$ of the unrelated patients with $\mathrm{FH}$. Of $\mathrm{FH}$-causing variants, $86 \%$ were variants of $L D L R$ and $13 \%$ were of $A P O B$. This is consistent with the global rate of $\mathrm{FH}$-causing variants. The most common variant was $A P O B$ c. $10579 \mathrm{C}>\mathrm{T}$ (p.Arg352Trp) (12.6\%), which has been reported in Chinese patients with $\mathrm{FH}^{3}$. Huang et al. also discussed the regional difference in FH-related variants found in East Asia.

We reported that pathogenic variants of $L D L R$ and $P C S K 9$ were found in $46 \%$ and $7.8 \%$ of unrelated Japanese patients with FH $(n=650)$, respectively ${ }^{4)}$. Of FH-causing variants, $85 \%$ were variants of $L D L R$ and $15 \%$ were of PCSK9. The c.94G $>$ A (p.Glu32Lys) variant comprised $88 \%$ of the pathogenic variants of
PCSK9. Worldwide, this variant has only been reported in one patient with $\mathrm{FH}$ in Korea ${ }^{5}$. Mabuchi et al. and we have reported that patients with $\mathrm{FH}$ harboring the c.94G $>$ A (p.Glu32Lys) variant have mild phenotypes compared with patients with $\mathrm{FH}$ harboring $L D L R$ pathogenic variants ${ }^{4,6}$. The c.94G > A (p.Glu32Lys) variant shows a mild FH phenotype compared with gain-of-function (GOF) variants of PCSK9 detected in countries other than Japan. Thus, the c.94G $>$ A (p.Glu32Lys) variant of PCSK9 is unique to Japan. We recently found the first Japanese family with $\mathrm{FH}$ due to the c.10580G $>$ A: p. (Arg3527Gln) variant of $A P O B$ although the frequency was low ${ }^{7)}$. The phenotype of $A P O B$ pathogenic variant carriers has been reported to be mild compared with that of $L D L R$ pathogenic variant carriers ${ }^{8)}$. The $L D L R$ pathogenic variants and PCSK9 GOF variants are definite $\mathrm{FH}$-causing variants, but the phenotype of $\mathrm{FH}$ caused by variants of $A P O B$ and PCSK9 other than these variants is mild. Thus, the second type of FH-causing gene/variant varies by country and population.

Patients with $\mathrm{FH}$ harboring no pathogenic variants of $L D L R, A P O B$, or PCSK9 comprised approximately $40 \%$ of the total unrelated patients with $\mathrm{FH}^{2,4)}$. Recently, rare variants of $A B C G 5$ and $A B C G 8$ have been reported in patients with $\mathrm{FH}^{9,10)}$. Tada et al. reported that rare and deleterious mutations of $A B C G 5$ or $A B C G 8$ were found in $8 \%$ in the 487 patients who were clinically diagnosed with FH in Japan ${ }^{9)}$. Reeskamp et al. reported that $2.4 \%$ of subjects in Netherlands's FH cohort carried putative pathogenic variants of $A B C G 5$ and $A B C G 8$ but had lower LDL-C levels compared with $\mathrm{FH}$ patients with an $L D L R$ variant ${ }^{10)}$. They concluded that these genes can partly explain the $\mathrm{FH}$ phenotype in some individuals but they might not cause $\mathrm{FH}$ inheritance

Address for correspondence: Mika Hori, Department of Endocrinology, Research Institute of Environmental Medicine, Nagoya University, Furo-cho, Chikusa-ku, Nagoya 464-8601, Japan E-mail: mihori@riem.nagoya-u.ac.jp

Received: June 29, $2021 \quad$ Accepted for publication: July 13, 2021

Copyright@2021 Japan Atherosclerosis Society

This article is distributed under the terms of the latest version of CC BY-NC-SA defined by the Creative Commons Attribution License. 
patterns. In recent years, whole-exome/genome sequencing has been increasingly implemented in genetic analysis for FH. It may be useful to search for novel FH-related genes/variants from LDL-Cassociated single-nucleotide polymorphisms from genome-wide association studies in the $\mathrm{FH}$ cohort of each country ${ }^{11)}$. The variants of $A B C G 5 / A B C G 8$ and other FH-related genes may reveal the $\mathrm{FH}$ phenotype by the presence of other genetic or environmental factors that affect cholesterol metabolism.

In conclusion, a cohort of larger size is needed to clarify the causative gene/variant underlying $\mathrm{FH}$ and improve genetic diagnosis rate. The regional or national $\mathrm{FH}$ registries, including genome information, could serve for detection and management of $\mathrm{FH}$ in each country/population.

\section{Conflicts of Interest}

None.

\section{References}

1) Benn M, Watts GF, Tybjærg-Hansen A and Nordestgaard BG: Mutations causative of familial hypercholesterolaemia: screening of 98098 individuals from the Copenhagen General Population Study estimated a prevalence of 1 in 217. Euro Heart J, 2016; 37: 1384-1394

2) Huang CC, Niu DM and Charng MJ: Genetic Analysis in a Taiwanese Cohort of 750 Index Patients with Clinically Diagnosed Familial Hypercholesterolemia. J Atheroscler Thromb, 2021;

3) Chiou K-R and Charng M-J: Genetic diagnosis of familial hypercholesterolemia in Han Chinese. J Clin Lipidol, 2016; 10: 490-496

4) Hori M, Ohta N, Takahashi A, Masuda H, Isoda R, Yamamoto S, Son C, Ogura M, Hosoda K, Miyamoto Y and Harada-Shiba M: Impact of LDLR and PCSK9 pathogenic variants in Japanese heterozygous familial hypercholesterolemia patients. Atherosclerosis, 2019; 289: 101-108
5) Han SM, Hwang B, Park TG, Kim DI, Rhee MY, Lee BK, Ahn YK, Cho BR, Woo J, Hur SH, Jeong JO, Park S, Jang Y, Lee MG, Bang D, Lee JH and Lee SH: Genetic testing of Korean familial hypercholesterolemia using whole-exome sequencing. PLoS One, 2015; 10: e0126706

6) Mabuchi H, Nohara A, Noguchi T, Kobayashi J, Kawashiri MA, Inoue T, Mori M, Tada H, Nakanishi C, Yagi K, Yamagishi M, Ueda K, Takegoshi T, Miyamoto S, Inazu $\mathrm{A}$ and Koizumi J: Genotypic and phenotypic features in homozygous familial hypercholesterolemia caused by proprotein convertase subtilisin/kexin type 9 (PCSK9) gain-of-function mutation. Atherosclerosis, 2014; 236: 54-61

7) Hori M, Takahashi A, Son C, Ogura M and HaradaShiba M: The first Japanese cases of familial hypercholesterolemia due to a known pathogenic APOB gene variant, c.10580 G>A: p.(Arg3527Gln). J Clin Lipidol, 2020; 14: 482-486

8) Real JT, Chaves FJ, Ejarque I, García-García AB, Valldecabres C, Ascaso JF, Armengod ME and Carmena $\mathrm{R}$ : Influence of LDL receptor gene mutations and the R3500Q mutation of the apoB gene on lipoprotein phenotype of familial hypercholesterolemic patients from a South European population. Euro J Hum Genet, 2003; 11: 959-965

9) Tada H, Okada H, Nomura A, Yashiro S, Nohara A, Ishigaki Y, Takamura $M$ and Kawashiri MA: Rare and Deleterious Mutations in ABCG5/ABCG8 Genes Contribute to Mimicking and Worsening of Familial Hypercholesterolemia Phenotype. Circ J, 2019; 83: 19171924

10) Reeskamp LF, Volta A, Zuurbier L, Defesche JC, Hovingh GK and Grefhorst A: ABCG5 and ABCG8 genetic variants in familial hypercholesterolemia. J Clin Lipidol, 2020; 14: 207-217.e207

11) Talmud PJ, Shah S, Whittall R, Futema M, Howard P, Cooper JA, Harrison SC, Li K, Drenos F, Karpe F, Neil HA, Descamps OS, Langenberg C, Lench N, Kivimaki M, Whittaker J, Hingorani AD, Kumari $M$ and Humphries SE: Use of low-density lipoprotein cholesterol gene score to distinguish patients with polygenic and monogenic familial hypercholesterolaemia: a case-control study. Lancet, 2013; 381: 1293-1301 